\title{
Antibodies to paraoxonase 1 are associated with oxidant status and endothelial activation in rheumatoid arthritis
}

Javier Rodríguez-Carrio*†, Mercedes Alperi-Lópezキ, Raquel López-Mejías§, Patricia López*,

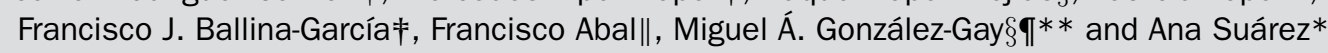

*Area of Immunology, Department of Functional Biology, University of Oviedo, Asturias, Spain

†Department of Microbiology and Biochemistry of Dairy Products, Instituto de Productos Lácteos de Asturias (IPLA-CSIC), Asturias, Spain †Department of Rheumatology, Hospital Universitario Central de Asturias, Asturias, Spain

§Epidemiology, Genetics and Atherosclerosis Research Group on Systemic Inflammatory Diseases, Rheumatology Division, Hospital Universitario Marqués de Valdecilla, IDIVAL, Santander, Spain

॥Centro de Salud Sariego, Servicio de Salud del Principado de Asturias, Asturias, Spain

IDepartment of Medicine, University of Cantabria, Santander, Spain

**Cardiovascular Pathophysiology and Genomics Research Unit, School of Physiology, Faculty of Health Sciences, University of the Witwatersrand, Johannesburg, South Africa

\begin{abstract}
Traditional and non-traditional cardiovascular (CV) risk factors underlie CV disease occurrence in rheumatoid arthritis (RA). Recently, a functional impairment of high-density lipoprotein (HDL) has been observed. Although the actual players are unknown, anti-HDLs were associated with altered lipid profile, decreased paraoxonase 1 (PON1) activity and CV disease in RA. Therefore, we aimed to evaluate whether the presence of antibodies against PON1 may be involved in this scenario. IgG anti-PON1 antibodies were quantified by ELISA in serum samples from 212 RA patients, 175 healthy controls ( $\mathrm{HC}$ ) and 54 subjects with traditional CV risk factors. A subgroup of $13 \mathrm{RA}$ patients was prospectively followed upon tumour necrosis factor- $\alpha$ (TNF $\alpha$ )-blockade. Serum PON1 activity, nitric oxide (NO) and total antioxidant capacity (TAC) were measured. Interferon- $\gamma$ (IFN $\gamma$ ), interleukin 8 (IL-8), monocyte chemotactic protein 1 (MCP-1), vascular endothelial growth factor (VEGF), soluble intercellular adhesion molecule (SICAM) and $\mathrm{TNF} \alpha$ serum levels were assessed by immunoassays. PON1 rs662 $(Q>R)$ status was studied by RT-PCR. IgG anti-PON1 antibodies are increased in RA patients compared with $\mathrm{HC}(P<0.0001)$ and CVR subjects $(P<0.001)$, even after correcting for total IgG levels. Although no associations with lipid profile were found, a positive correlation with Health Assessment Questionnaire (HAQ) was observed $(r=0.215, P=0.004)$. Anti-PON1 antibodies were associated with PON1 activity, NO and TAC, a rs662-mediated gene-dosage effect being found. Similarly, anti-PON1 antibodies were associated with sICAM serum levels in univariate and multivariate models. Finally, these antibodies were not affected by TNF $\alpha$-blockade. Anti-PON1 antibodies can be responsible of PON1 impairment in RA patients, with a potential impact on biomarkers of oxidative status and endothelial activation. A gene-environment interaction of rs662 variants is supported.
\end{abstract}

Key words: anti-paraoxonase 1 antibodies, cardiovascular, high-density lipoproteins, paraoxonase, rheumatoid arthritis.

\section{INTRODUCTION}

Rheumatoid arthritis (RA) is associated with increased rates of cardiovascular disease (CVD) morbidity and mortality [1]. Since traditional CV risk factors fail to fully account for this excess risk, disease-related features, such as chronic inflammation and immune dysregulation are thought to play a role [2,3].

Interestingly, a cross-talk between these two groups of risk factors has been proposed [4]. Altered lipoprotein profile is a common feature of RA, especially in high disease activity states

Abbreviations: ACPA, anti-citrullinated peptide antibodies; APS, anti-phospholipid syndrome; AU, arbitrary units; CV, cardiovascular; CVD, cardiovascular disease; CVR, subjects with traditional CV risk factors; DAS28, disease activity score 28-joints; eNOS, endothelial nitric oxide synthase; HAQ, Health Assessment Questionnaire; HC, healthy controls; HDL, high-density lipoprotein; IL-8, interleukin 8; LDL, low-density lipoprotein; MCP-1, monocyte chemotactic protein 1; NO, nitric oxide; PON1, paraoxonase 1; RA, rheumatoid arthritis; RF, rheumatoid factor; sICAM, soluble intercellular adhesion molecule; TAC, total antioxidant capacity; TNF $\alpha$, tumour necrosis factor- $\alpha$, vascular endothelial growth factor. 
$[5,6]$. Actually, the term 'lipid paradox' has been coined to cover this topic [7]. Upon treatment, normalization of disease activity and thus, inflammatory burden, led to normalization of lipid levels to variable degrees, depending on the drug approach used $[5,8]$. These findings support the involvement of different immune pathways in the maintenance of the lipid profile, although some authors proposed that inflammation cannot be the only underlying factor [5]. In recent years, in addition to altered levels, compromised high-density lipoprotein (HDL) functionality has been also reported in RA $[9,10]$, hence expanding the topic of 'lipid paradox' to 'HDL dysfunction'. However, how the interplay between lipids, immune pathways and CVD is orchestrated remains vaguely understood.

Among the novel functions for HDL, anti-inflammatory and antioxidant capacities are of outstanding relevance. Antioxidant functionality is mostly developed by the calcium-dependent esterase paraoxonase 1 (PON1) [11]. PON1 enzymatic activity prevents the oxidization of low-density lipoproteins (LDL) as well as the inactivation of already formed oxidized phospholipids [11]. Moreover, PON1 protects HDL itself from oxidation, thus playing a crucial role on antioxidant capacity of HDL [12]. The role of oxidized lipoproteins in the early stages of atherosclerosis development, involving immune-mediated mechanisms and the up-regulation of adhesion molecules, accounts for the role of the antioxidant activity of PON1 in preventing atherosclerosis $[13,14]$. PON1 activity is under genetic control by a number of polymorphisms, a single nucleotide located at position +192 being the most important [15]. Moreover, controversy on the influence of rs662 variants $[16,17]$ may suggest that geneenvironment interactions are responsible of the final PON1 activity outcome $[18,19]$. However, what the clinical significance for PON1 impairment is remains controversial.

In line with the emerging role of autoantibodies in CVD pathogenesis, we have recently characterized the involvement of antibodies against high-density lipoproteins (anti-HDL) on lipid profiles, therapy outcome and PON1 activity in RA [20,21]. Since other groups have revealed the presence of anti-apolipoprotein A1 antibodies [22] and due to the complexity of the HDL structure, we wondered whether HDL dysfunction may be linked to other lipoprotein components. Therefore, in the present report we aimed (i) to analyse whether PON1 is a new autoimmune target in RA, (ii) to investigate whether anti-PON1 antibodies may be linked to lipid profiles and inflammatory mediators, (iii) to evaluate whether anti-PON1 are linked to a compromised PON1 functionality and its association with PON1 rs662 genetic variants and finally (iv) to analyse whether anti-PON1 antibodies might be affected by immunomodulatory treatment.

\section{MATERIALS AND METHODS}

\section{Patients and controls}

This cross-sectional case-control study involved three different groups of individuals recruited (Table 1). RA patients, all fulfilling $2010 \mathrm{ACR} / \mathrm{EULAR}$ classification criteria, were enrolled from the Department of Rheumatology at Hospital Universitario
Central de Asturias. A complete clinical examination, including disease activity score 28-joints (DAS28) calculation, was performed on all patients on their clinic appointment and a blood sample was drawn by venipuncture. Clinical records were retrospectively revised so as to register traditional $\mathrm{CV}$ risk factors and the history of CV events. Definition and classification of $\mathrm{CV}$ events and traditional risk factors (hypertension, diabetes, dyslipidaemia, obesity and smoking) were performed as previously established [21]. Similarly, a subgroup of 13 RA patients [12 women, median age 43 (range: 30-65), DAS28 5.08(1.93), $38.5 \% \mathrm{RF}+, 46.1 \% \mathrm{ACPA}+]$, biological-naïve and candidates for tumour necrosis factor- $\alpha$ (TNF $\alpha$ )-blockers, was prospectively followed for 3 months. A blood sample was obtained immediately before (baseline, pre-treatment) as well as 3-months after initiation of anti-TNF $\alpha$ therapy (post-treatment) [11 golimumab (50 $\mathrm{mg} / \mathrm{month}$, subcutaneous) and 2 etanercept $(50 \mathrm{mg} /$ week, subcutaneous)]. All patients were in concomitant methotrexate and $10(76.9 \%)$ were also in low-dose glucocorticoid therapy. Clinical response was evaluated by EULAR criteria.

Simultaneously, 175 gender- and age-matched healthy volunteers $(\mathrm{HC})$ were recruited from the same population and a group of 54 individuals with traditional CV risk factors (Table 1) was recruited from their primary healthcare centre.

Automated serum lipids analysis was carried out on all the participants from fresh blood samples. Serum samples were stored at $-80 \mathrm{oC}$ until laboratory measurements were performed. Approval for the study was obtained from the Institutional Review Board (Comité de Ética Regional de Investigación Clínica), in compliance with the Declaration of Helsinki. All the participants gave written informed consent prior to their inclusion in the study.

\section{Determination of IgG anti-PON1 antibodies}

IgG anti-PON1 antibodies were measured in serum samples by an in-house ELISA. Microtiter Maxisorp plates (Nunc) were half-coated with $2 \mu \mathrm{g} / \mathrm{ml}$ human paraoxonase-1 protein (Abcam) in carbonate buffer ( $\mathrm{pH}$ 9.6) (half test) or carbonate buffer alone (half control) overnight at $4 \mathrm{oC}$. Plates were blocked with PBS containing $2 \%$ BSA (Sigma) for $2 \mathrm{~h}$ at $37 \mathrm{oC}$. Then, serum samples diluted 1:100 in PBS $0.1 \%$ BSA and standard curves from pooled sera (dilutions 1:20-1:2560) were incubated for $2 \mathrm{~h}$. After washing with TBS-Tween $20(0.05 \%)$, alkaline phosphatase-conjugated anti-human IgG (1:2000) (Immunostep) was added and incubated for $1 \mathrm{~h}$ with gentle shaking. Finally, the plate was washed with TBS and $p$-nitrophenylphosphate (Sigma) in diethanolamine buffer was added as substrate. Absorbance at $405 \mathrm{~nm}$ was recorded, anti-PON1 arbitrary units (AU) were calculated for each sample according to those from the standard curve after subtracting absorbance from the half control to that of the half test.

Similarly, total IgG was quantified by conventional ELISA techniques. Anti-PON1 AU values were corrected using total IgG levels (anti-PON1/IgG).

\section{Determination of IgG anti-HDL antibodies}

IgG anti-HDL antibodies were quantified as previously reported by our group [21]. 


\section{Table 1 Demographic and clinical features in the different study groups}

Continuous variables were summarized as median (interquartile range) or mean \pm S.D., as appropriated, and $n$ (\%) for categorical ones, unless otherwise stated. Differences among the three study groups were analysed by $\chi^{2}$ or Kruskal-Wallis tests. CRP, C-reactive protein; ESR, erythrocyte sedimentation rate; NSAIDs, non-steroidal anti-inflammatory drugs.

\begin{tabular}{|c|c|c|c|c|}
\hline & HC $(n=175)$ & RA $(n=212)$ & $\operatorname{CVR}(n=54)$ & P-value \\
\hline \multicolumn{5}{|l|}{ Demographic parameters } \\
\hline Gender (f/m) & $102 / 35$ & $175 / 37$ & $38 / 16$ & 0.071 \\
\hline Age at sampling, years (mean (range)) & $51(23-80)$ & $54(18-87)$ & $54(33-68)$ & 0.300 \\
\hline Total-cholesterol, mg/dl & $204.61 \pm 34.35$ & $207.42 \pm 35.71$ & $216.97 \pm 45.25$ & 0.185 \\
\hline HDL-cholesterol, mg/dl & $58.83 \pm 13.81$ & $60.56 \pm 17.60$ & $57.39 \pm 14.06$ & 0.394 \\
\hline LDL-cholesterol, mg/dl & $125.38 \pm 30.05$ & $122.60 \pm 32.38$ & $135.54 \pm 35.25$ & 0.080 \\
\hline Total/HDL-cholesterol ratio & $3.67 \pm 1.00$ & $3.72 \pm 1.35$ & $3.93 \pm 1.13$ & 0.211 \\
\hline \multicolumn{5}{|l|}{ Clinical features } \\
\hline Disease duration (years) (range) & & $2.75(0-30)$ & & \\
\hline Recruited at onset, $n(\%)$ & & $47(22.1)$ & & \\
\hline Age at diagnosis (years) & & $50.00(17.00)$ & & \\
\hline $\mathrm{CRP}(\mathrm{mg} / \mathrm{dl})$ & & $1.00(2.63)$ & & \\
\hline $\mathrm{ESR}(\mathrm{mm})$ & & $18.00(23.00)$ & & \\
\hline DAS28 score & & $3.73(2.24)$ & & \\
\hline HAQ & & $0.87(1.25)$ & & \\
\hline $\mathrm{RF}+, n(\%)$ & & $119(56.1)$ & & \\
\hline $\mathrm{ACPA}+, n(\%)$ & & $121(57.0)$ & & \\
\hline \multicolumn{5}{|l|}{ Treatments, $n(\%)$} \\
\hline None or NSAIDs & & $47(22.1)$ & & \\
\hline Glucocorticoids & & $103(48.5)$ & & \\
\hline Methotrexate & & $139(65.5)$ & & \\
\hline TNF $\alpha$-blockers & & $48(22.6)$ & & \\
\hline Tocilizumab & & $12(5.6)$ & & \\
\hline Statins & & $24(11.3)$ & & \\
\hline \multicolumn{5}{|l|}{ Traditional CV risk factors, $n(\%)$} \\
\hline Hypertension & & $65(30.6)$ & $34(62.9)$ & \\
\hline Dyslipidaemia & & $52(34.5)$ & $21(38.8)$ & \\
\hline Diabetes & & $22(10.3)$ & $20(37.0)$ & \\
\hline Obesity $(n=129)$ & & $29(13.6)$ & $21(38.8)$ & \\
\hline Smoking & & $74(34.9)$ & $34(62.9)$ & \\
\hline Previous CV events, $n$ (\%) & & $38(17.9)$ & & \\
\hline
\end{tabular}

\section{Analysis of PON1 activity}

PON1 activity was quantified as previously described [20] using paraoxon (Sigma) as substrate. A unit (U) of PON1 activity was expressed as micromoles of $p$-nitrophenol formed per minute per millilitre of serum.

\section{Quantification of cytokine serum levels}

Interleukin 8 (IL-8) and vascular endothelial growth factor (VEGF) serum levels were quantified using a Cytometric Bead Array Flex Set (BD) in a FACS Canto II flow cytometer using FCAP Array v.1.0.1, following the manufacturer's instructions. The detection limits were 1.2 and $4.5 \mathrm{pg} / \mathrm{ml}$ respectively.

Interferon- $\gamma$ (IFN $\gamma$ ) serum levels were assessed using an OptEIA kit (BD) following the manufacturer's instructions (detection limit: $0.58 \mathrm{pg} / \mathrm{ml}$ ). Levels of $\mathrm{TNF} \alpha$, monocyte chemotactic protein 1 (MCP-1) and sICAM-1 were quantified using Mini ELISA Development Kits (PeproTech), according to the man- ufacturer's instructions (detection limits were: 3.9, 8 and 23.44 $\mathrm{pg} / \mathrm{ml}$ respectively).

\section{Analysis of total antioxidant capacity}

Serum total antioxidant capacity (TAC) was assessed by means of a spectrophotometric method based on the cupric reducing antioxidant capacity (CUPRAC method) using a commercial kit (TAC Assay Kit, Sciencell Research Laboratories). Serum TAC was expressed as Trolox equivalent units (T-Eq).

\section{Assessment of nitric oxide serum levels}

Nitric oxide (NO) levels were indirectly quantified through the measurement of the stable metabolites nitrite and nitrate $\left(\mathrm{NO}_{x}\right)$ in serum. These products were measured by means of the Griess reaction using a commercial kit [Nitric Oxide (total) detection kit, Enzo Life Sciences], following the protocol provided by the manufacturer. $\mathrm{NO}_{x}$ detection limit was $3.1 \mu \mathrm{M}$. Serum samples were treated with zinc sulfate $\left(\mathrm{ZnSO}_{4}\right)$ (less than $1 / 20$ th of the 

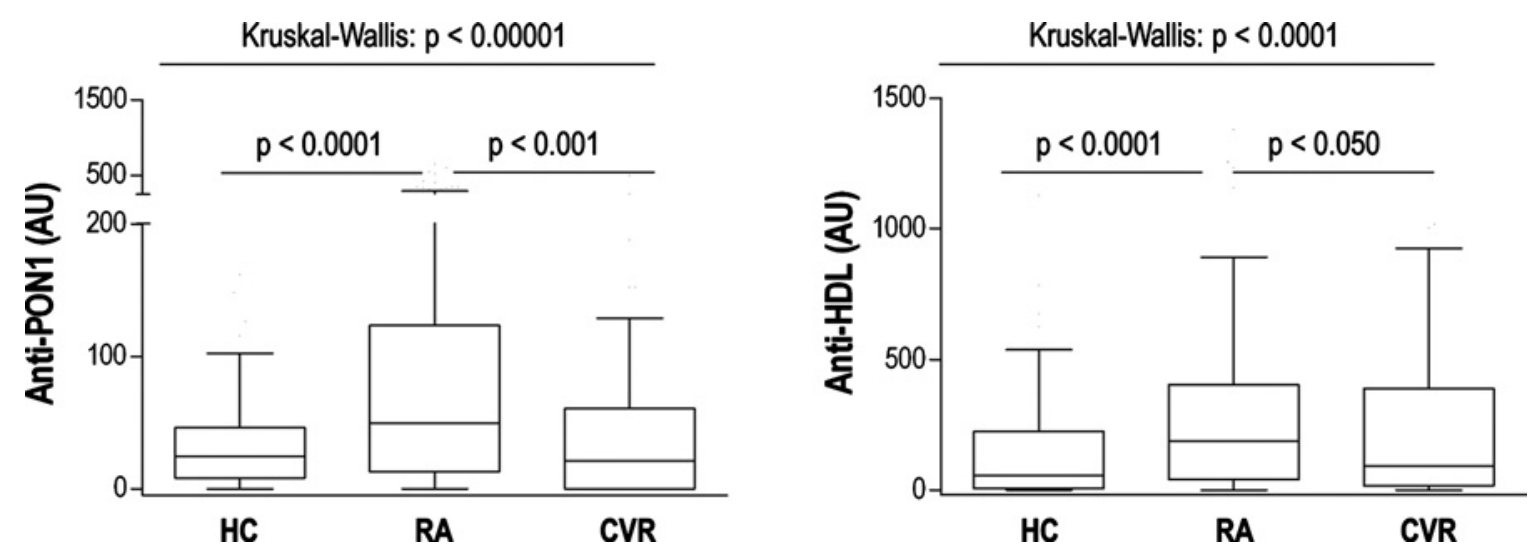

Figure 1 Levels of IgG anti-PON1 and anti-HDL antibodies in the different study groups

Results are shown as box plots, where the boxes represent the 25th to 75th percentiles, the lines within the boxes represent the median, and the lines outside the boxes represent the minimum and maximum values. Differences were assessed by Kruskal-Wallis and Dunn-Bonferroni post hoc tests. HC $(n=172)$, RA $(n=212)$, CVR $(n=54)$.

total volume) to allow protein precipitation, as described in [23]. Efficiency of protein precipitation was evaluated by protein quantification by the Bradford Assay.

\section{P0N1 rs662 genotyping}

DNA was obtained from whole peripheral blood using standard methods. The PON1 rs662 polymorphism was genotyped with TaqMan predesigned single-nucleotide polymorphism (SNP) genotyping assays (C_2548962_20) in a 7900 HT Real-Time PCR system. PCR cycles (total volume: $4 \mu \mathrm{l}$ ) were carried out as follows: denaturation at $95^{\circ} \mathrm{C}$ for $10 \mathrm{~min}, 45$ cycles of denaturation at $92^{\circ} \mathrm{C}$ for $15 \mathrm{~s}$, and then annealing and extension at $60^{\circ} \mathrm{C}$ for $1 \mathrm{~min}$.

\section{Statistical analysis}

Data are expressed as median (interquartile range) or mean \pm S.D., as appropriated. Categorical variables were expressed as $n(\%)$ and analysed using $\chi^{2}$ tests. Correlations were assessed by Spearman rank's test, whereas differences among groups were analysed by Kruskal-Wallis (Dunn-Bonferroni correction for multiple comparisons test) or Mann-Whitney $U$ tests. An ANCOVA model was used to evaluate the simultaneous effect of anti-PON1 antibodies and rs662 variants on PON1 activity. Variables were log-transformed to achieve normal distribution prior to multiple regression analyses and adjusted $\beta, B$ coefficients and $95 \%$ confidence intervals (CI) were calculated. A $P$-value $<0.050$ was considered as the limit of signification. Statistical analyses were performed under SPSS 19.0 and Graph Pad 5.0 .

\section{RESULTS}

\section{IgG anti-PON1 antibodies are increased in RA patients}

The levels of IgG anti-PON1 and anti-HDL antibodies were quantified in serum samples from the study groups summarized in
Table 1. IgG anti-PON1 antibodies were found to be increased in RA patients compared with HC and CVR populations (Figure 1). Although no correlation was found with anti-HDL levels ( $r=0.087, P=0.211)$, higher anti-PON1 levels were observed in patients with elevated anti-HDL levels (levels $>90$ th anti$\mathrm{HDL} / \mathrm{IgG}$ in the HC population, $P=0.043$ ). Increased anti-PON1 antibodies in RA cannot be attributed to a general IgG production in the context of autoimmunity, since differences remained after correction for total IgG levels [anti-PON1/IgG: 8.63 (15.34) compared with 10.92 (35.62); $P=0.015]$.

Therefore, we evaluated whether IgG anti-PON1 antibodies may be associated with a subgroup of RA patients with specific clinical or immunological features. Anti-PON1/IgG levels were neither correlated to disease activity $(r=0.078, P=0.289)$ nor duration $(r=0.123, P=0.083)$, although a positive correlation was found with Health Assessment Questionnaire (HAQ) score ( $r=0.215, P=0.004)$. Moreover, rheumatoid factor (RF) or anti-citrullinated peptide antibodies (ACPA) positivity was not associated with anti-PON1 levels $(P=0.893$ and $P=0.159$ respectively). Interestingly, the history of previous $\mathrm{CV}$ events was not related to anti-PON1 levels $(P=0.697)$, and equivalent results were obtained for the presence of traditional CV risk factors (all $P>0.050$ ), in line with the results observed in the CVR group. Finally, no effect of immunomodulatory therapies was found on anti-PON1 levels (all $P>0.050$ ).

Due to the role of PON1 as a component of HDL particles, we wondered whether anti-PON1 might be associated with an impaired lipid blood profile in RA. Anti-PON1/IgG was not correlated to HDL levels in the whole group of RA patients ( $r=-0.027, P=0.718$ ) or after stratification according to disease duration: patients at onset $(r=-0.237, P=0.136 ; n=47)$ and established $(r=0.029, P=0.736 ; n=165)$. Furthermore, anti-PON1 levels failed to predict those of HDL in a multivariate regression analysis including age, gender, disease duration, and treatment usages as potential confounders $(B[95 \% \mathrm{CI}], P$-value: $-0.013[-0.044,0.018], P=0.393)$. Equivalent results were obtained when the ratio total cholesterol/HDL was studied. 
Table 2 Serum levels of pro-inflammatory cytokines and biomarkers of endothelial activation and dysfunction Variables are summarized as median (interquartile range) or mean \pm S.D. and differences were assessed by Kruskal-Wallis and Dunn-Bonferroni post hoc tests. Differences in the multiple comparison tests are indicated as $* P<0.050, * * P<0.010$ and $* * * P<0.001$ with respect to the $\mathrm{HC}$ population. $\mathrm{NO}_{x}$, nitrite/nitrate.

\begin{tabular}{|c|c|c|c|c|}
\hline & HC & $\mathbf{R A}$ & CVR & P-value \\
\hline $\mathrm{TNF} \alpha(\mathrm{pg} / \mathrm{ml})$ & $93.94(201.52)$ & $246.00(282.40) * * *$ & $151.70(145.45)$ & $<0.0001$ \\
\hline $\mathrm{IFN} \gamma(\mathrm{pg} / \mathrm{ml})$ & $3.29(7.35)$ & $4.48(5.02) *$ & $4.35(16.6)^{*}$ & 0.019 \\
\hline IL-8 (pg/ml) & $14.84(11.48)$ & $43.08(17.07) * * *$ & $14.42(8.88)$ & $<0.0001$ \\
\hline VEGF (pg/ml) & 85.19 (44.34) & $113.30(44.93) * * *$ & 76.54 (50.62) & $<0.0001$ \\
\hline MCP-1 (pg/ml) & $247.00(303.80)$ & $303.70(398.20) *$ & $287.50(283.90)$ & 0.036 \\
\hline sICAM-1 (pg/ml) & $158.80(139.80)$ & $230.30(190.00) * *$ & $201.10(132.90)$ & 0.005 \\
\hline $\mathrm{NO}_{x}(\mu \mathrm{M})$ & $22.14 \pm 18.41$ & $20.12 \pm 21.23$ & $16.25 \pm 17.49$ & 0.181 \\
\hline
\end{tabular}

All these results revealed a specific increase in IgG anti-PON1 antibodies in RA patients which is not associated with traditional $\mathrm{CV}$ risk factors, clinical parameters or lipid profile.

\section{IgG anti-PON1 antibodies are linked to an impaired PON1 activity, oxidative stress and endothelial activation}

Next, to analyse the possible impact of anti-PON1 on HDL functionality, PON1 activity and some biomarkers of oxidative status, inflammation and endothelial activation were measured. Serum PON1 activity was decreased in RA patients $(287.10 \pm 123.88 \mathrm{U})$ compared with both HC $(336.57 \pm 127.21$ U, P(DunnBonferroni $<0.010)$ and CVR subjects $(336.27 \pm 134.70 \mathrm{U}$, $P($ Dunn-Bonferroni $)<0.050)$. Interestingly, a negative correlation was found between PON1 activity and anti-PON1/IgG levels in RA ( $r=-0.223, P<0.001)$, this association being stronger in patients with established disease $(r=-0.258, P<0.001)$ and absent from patients recruited at onset $(r=-0.027, P=0.855)$. No associations between anti-PON1 levels and PON1 activity were found in $\mathrm{HC}(r=0.103, P=0.254)$ or CVR $(R=-0.126$, $P=0.365$ ).

Similarly, serum TAC was decreased in RA $(3.90 \pm 0.88 \mathrm{mM}$ T-Eq) compared with HC $(4.62 \pm 1.03 \mathrm{mM} \mathrm{T-Eq})$ and CVR individuals $(4.50 \pm 0.95 \mathrm{mM} \mathrm{T}$-Eq) $[P($ Dunn-Bonferroni $)<0.001$, in both cases]. A slight correlation was found between TAC and anti-PON1 antibodies in RA patients with established disease $(r=-0.158, P=0.040)$. However, no association was detected in patients recruited at onset $(r=0.077, P=0.609)$, where a stronger decrease in TAC was observed compared with their established counterparts (3.66 \pm 0.68 compared with $4.02 \pm 0.92 \mathrm{mM} \mathrm{T}$-Eq, $P=0.020$ ).

Finally, the associations between anti-PON1 antibodies and serum levels of pro-inflammatory cytokines (TNF $\alpha, \operatorname{IFN} \gamma$ and IL-8) as well as biomarkers of endothelial activation (VEGF, MCP-1 and sICAM-1) and dysfunction $\left(\mathrm{NO}_{x}\right)$ were analysed (Table 2). Interestingly, anti-PON $1 / \operatorname{IgG}$ levels were correlated to those of sICAM-1 in RA $(r=0.226, P=0.010)$. Additionally, anti-PON1/IgG levels were found to be slightly correlated to $\mathrm{NO}_{x}$ serum levels in RA $(r=-0.183, P=0.018)$.

Therefore, IgG anti-PON1 antibodies seem to have a detrimental effect on PON1 activity, oxidative status and endothelial activation.

\section{Effects of anti-PON1 antibodies are dependent on PON1 rs662 genotype}

Due to the role of rs 662 genetic variants on the functional activity of PON1, RA patients were stratified according to rs662 status and the influence of anti-PON1 antibodies on PON1 activity, TAC, sICAM and $\mathrm{NO}_{x}$ serum levels was analysed.

Surprisingly, the negative association between PON1 activity and anti-PON1 levels was restricted to patients harbouring the QQ genotype, being absent from their QR- or RR-counterparts (Table 3). Of note, no differences were observed in anti-PON1 levels among rs662 variants. Accordingly, an ANCOVA analysis confirmed an independent effect (interaction $P=0.486$ ) of both rs662 status $(P<0.0001)$ and anti-PON1 levels $(P=0.015)$. Therefore, a multivariate linear regression analysis was conducted after adjusting for disease parameters and treatments (Table 4), hence confirming the independent role of anti-PON1 antibodies as predictors of impaired PON1 activity in RA. Of note, a slight effect of TNF $\alpha$-blockers was observed.

Likewise, the analysis of the association between anti-PON1 levels and serum TAC revealed a notable rs662-driven genedosage effect, which mirror that of found for the correlation between PON1 activity and TAC (Table 3). A similar effect was observed for $\mathrm{NO}_{x}$ serum levels. Interestingly, anti-PON1 antibodies remained associated with $\mathrm{NO}_{x}$ serum levels after adjusting for DAS28 score, disease duration and treatments as potential confounders ( $B[95 \% \mathrm{CI}], P:-5.234[-9.319,-1.148], 0.013)$. On the other hand, sICAM serum levels were not affected by rs662 variants, and its association with anti-PON1 antibodies remained significant after controlling for potential confounders (Table 5).

Overall, these findings revealed a link between anti-PON1 antibodies-mediated PON1 activity impairment and decreased antioxidant capacity in RA, and point to rs662 variants as key regulators of the outcome of these associations. Similarly, a role for these antibodies in endothelial dysfunction can be expected.

\section{IgG anti-PON1 antibodies, PON1 activity and TAC upon TNF $\alpha$ blockade}

Since TNF $\alpha$-blockers have been described to restore HDL levels and function in RA patients, we wondered whether a therapyinduced fluctuation of anti-PON1 antibodies may underlie these findings. Then, we tested this hypothesis in a subgroup of 13 
Table 3 Effect of rs662 polymorphism on the impact of IgG anti-PON1 antibodies

Differences among genotypes were assessed by Kruskal-Wallis tests and correlations were analysed by Spearman rank's test. $\mathrm{NO}_{x}$, serum nitrite/nitrates.

\begin{tabular}{llllr}
\hline & QQ $(\boldsymbol{n}=\mathbf{9 5})$ & QR $(\boldsymbol{n}=\mathbf{6 9})$ & RR $(\boldsymbol{n}=\mathbf{2 2})$ & P-value \\
\hline Anti-PON1/lgG & $11.12(35.62)$ & $12.60(35.33)$ & $14.19(68.39)$ & 0.548 \\
PON1 activity (unit) & $217.57 \pm 86.08$ & $345.96 \pm 115.12$ & $418.33 \pm 101.17$ & $<0.0001$ \\
TAC $(\mathrm{mM}, \mathrm{T}-\mathrm{Eq})$ & $3.99 \pm 0.91$ & $3.71 \pm 0.86$ & $3.85 \pm 0.91$ & 0.106 \\
$\mathrm{NO}_{x}(\mu \mathrm{M})$ & $18.25 \pm 16.52$ & $18.97 \pm 15.96$ & $18.41 \pm 9.06$ & 0.792 \\
sICAM-1 $(\mathrm{pg} / \mathrm{ml})$ & $226.80(168.92)$ & $273.25(208.56)$ & $244.31(278.16)$ & 0.507 \\
Correlations $(r, p)$ & & & & \\
Anti-PON1 - PON1 activity & $r=-0.369$ & $r=-0.158$ & $r=-0.310$ & $P=0.160$ \\
& $P=0.0002$ & $P=0.199$ & $r=0.150$ & $P=0.567$ \\
Anti-PON1 - TAC & $r=-0.290$ & $r=-0.259$ & $r=0.123$ \\
& $P=0.015$ & $P=0.056$ & $P=0.639$ \\
PON1 activity - TAC & $r=0.325$ & $r=0.154$ & $r=-0.453$ \\
Anti-PON1 - NO ${ }_{x}$ & $P=0.006$ & $P=0.241$ & $P=0.180$ \\
\end{tabular}

\section{Table 4 Effect of rs662 polymorphism and IgG anti-PON1} levels on PON1 activity

$R=0.648 ; R^{2}=0.438$. Multivariate linear regression analysis adjusted for CRP, ESR, DAS28 score, traditional CV risk factors and treatments using PON1 activity as dependent variable. ESR, erythrocyte sedimentation rate.

\begin{tabular}{lrcc}
\hline & $\boldsymbol{\beta}$ & $\boldsymbol{B}[\mathbf{9 5} \% \mathbf{C I}]$ & $\boldsymbol{P}$-value \\
\hline Anti-PON1/IgG & -0.245 & $-0.073[-0.109,-0.036]$ & $<0.001$ \\
rs662 & 0.557 & $0.167[0.130,0.203]$ & $<0.0001$ \\
Disease duration & -0.117 & $-0.022[-0.051,-0.007]$ & 0.143 \\
ESR & 0.004 & $0.001[-0.022,0.023]$ & 0.906 \\
DAS28 & 0.014 & $0.002[-0.024,0.028]$ & 0.961 \\
Glucocorticoids & 0.019 & $0.008[-0.046,0.061]$ & 0.778 \\
Methotrexate & 0.111 & $0.049[-0.011,0.109]$ & 0.111 \\
TNF $\alpha$-blockers & -0.166 & $-0.080[-0.146,-0.015]$ & 0.034 \\
Statins & -0.066 & $-0.042[-0.122,0.037]$ & 0.295 \\
Tocilizumab & -0.041 & $-0.037[-0.155,0.082]$ & 0.542 \\
\hline
\end{tabular}

biologic-naïve RA patients, candidates for anti-TNF $\alpha$ therapy, who were recruited and prospectively followed for 3 months.

$\mathrm{TNF} \alpha$-blockade was associated with decreasing $\mathrm{TNF} \alpha$ serum levels in patients exhibiting a good clinical response ( $n=5,451.05 \pm 265.98$ compared with $150.14 \pm 153.47 \mathrm{pg} / \mathrm{ml}$, $P=0.045)$, but not in the no-responder group $(n=8, P=0.451)$. No effect of TNF $\alpha$-blockers was found on anti-PON1 antibodies, and equivalent results were observed for PON1 activity, TAC and $\mathrm{NO}_{x}$ levels (Figure 2). Similarly, no differences were observed when patients were grouped by EULAR response or rs662 variants (QQ: $n=7$, QR: $n=5$, RR: $n=1$ ) in any of the variables studied.

Consequently, our results suggest that anti-PON1 antibodies are not influenced by anti-TNF $\alpha$ agents, hence underlining that other strategies may be needed to counteract the anti-PON1mediated PON1 impairment and, therefore, its relevance to the antioxidant status.
Table 5 Association between anti-PON1 antibodies and sICAM-1 serum levels

$R=0.611 ; R^{2}=0.374$. Multivariate linear regression analysis using sICAM-1 serum levels as dependent variable. BMI, body mass index; ESR, erythrocyte sedimentation rate.

\begin{tabular}{lrrr}
\hline & \multicolumn{1}{c}{$\boldsymbol{\beta}$} & \multicolumn{1}{c}{$\boldsymbol{B}$ [95\% Cl] } & $\boldsymbol{P}$-value \\
\hline Anti-PON1/IgG & 0.494 & $0.159[0.065,0.2253]$ & $<0.001$ \\
rs662 & 0.043 & $0.014[-0.076,0.104]$ & 0.755 \\
Disease duration & -0.140 & $-0.080[-0.246,0.086]$ & 0.341 \\
ESR & 0.018 & $0.009[-0.146,0.164]$ & 0.907 \\
DAS28 & -0.058 & $-0.059[-0.391,0.272]$ & 0.721 \\
BMI & -0.059 & $-0.003[-0.018,0.012]$ & 0.693 \\
Hypertension & 0.166 & $0.080[-0.045,0.205]$ & 0.204 \\
Diabetes & 0.193 & $0.182[-0.083,0.446]$ & 0.175 \\
Smoking & 0.213 & $0.105[-0.018,0.227]$ & 0.092 \\
Glucocorticoids & -0.093 & $-0.045[-0.176,0.086]$ & 0.492 \\
Methotrexate & -0.070 & $-0.039[-0.175,0.097]$ & 0.569 \\
TNF $\alpha$-blockers & 0.069 & $0.033[-0.115,0.181]$ & 0.660 \\
Statins & 0.221 & $0.137[-0.051,0.325]$ & 0.149 \\
Tocilizumab & -0.011 & $-0.007[-0.215,0.201]$ & 0.944 \\
\hline
\end{tabular}

\section{DISCUSSION}

Although extensive links between autoimmunity and CV disease have been reported, the actual mechanisms and mediators involved remain elusive. In recent years, a growing body of evidence strongly highlights a role for autoantibodies in the development of CVD [24]. In the present study, we described for the first time the IgG anti-PON1 antibodies as the new potential players in this scenario.

The presence of IgG anti-PON1 antibodies can explain, at least in part, the decreased PON1 activity reported in RA $[10,25,26]$. Actually, these antibodies may be responsible of the anti-HDL impairment of PON1 activity described by our group [21] and others $[22,27]$ in different conditions, and they can also 

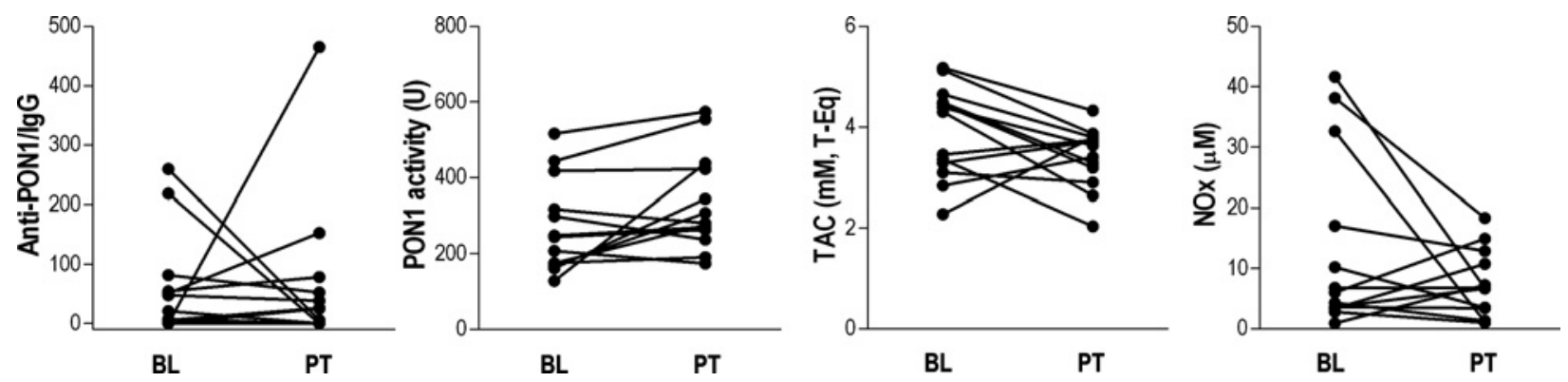

Figure 2 Effect of TNF $\alpha$-blockade on anti-PON1/IgG levels, PON1 activity, TAC and NO ${ }_{x}$ serum levels

Changes in anti-PON1/IgG, PON1 activity, serum TAC and $\mathrm{NO}_{x}$ levels upon TNF $\alpha$-blockade were analysed in a group of 13 biological-naïv RA patients. Differences between pre-treatment (BL, baseline) and at the end of 3 months of anti-TNF $\alpha$ therapy (PT, post-treatment) were evaluated by Wilcoxon paired test. No differences were found for anti-PON1/IgG $(P=0.969)$, PON1 $(P=0.068)$, TAC $(P=0.098)$ and $\mathrm{NO}_{x}(P=0.162)$.

explain the PON1 impairment in the absence of traditional CV risk factors. However, anti-PON1 antibodies were not related to an impaired blood lipid profile and history of past CV events, as reported for anti-HDL antibodies [21]. Taking into account the role for PON1 activity and lipid profile in CVD development, the findings herein presented may suggest that PON1 impairment could be necessary but not sufficient to promote CVD, at least in the context of autoimmune diseases. This notion is supported by the fact that individuals exhibiting high PON1 activity (i.e. those harbouring QR and RR rs662 variants) are not totally protected against CVD $[28,29]$. Similarly, although PON1 knockout mice exhibited enhanced lipoprotein oxidation, their double PON1/ApoE knockout counterparts exhibited a true accelerated atherosclerosis development [30], hence suggesting that additional mechanisms are needed as a 'second hit' to promote CVD occurrence. The interaction between PON1 and Apo A1 may support this notion [31,32].

An outstanding finding of our study is the association between anti-PON1 antibodies and the antioxidant capacity of serum. On the one hand, the impact of PON1 impairment out of the HDLPON1 axis remains unclear in the current literature. We have found that anti-PON1 levels are connected with a decrease antioxidant defence. Decreased antioxidant capacity has been previously linked to disability, poor quality of life and frailty in other conditions [33,34]. Our findings relating decreased TAC and HAQ score are in accordance with these pieces of evidence and confirm the clinical relevance of anti-PON1 antibodies and impaired antioxidant capacity in RA. As a consequence, this study supports a role for anti-PON1 antibodies as players of the HDL dysfunction phenomenon [35], which has been linked to a proinflammatory milieu [36,37]. On the other hand, several authors have previously related the oxidative status to the inflammatory burden, mainly in the context of CV risk and inflammatory conditions [13]. Actually, PON1 knockout mice exhibited an increased oxidative status with enhanced lipid peroxidation [38]. However, in human diseases mechanistic insight is lacking. Our results support that anti-PON1 antibodies may be the missing link between autoimmunity, oxidative stress and CVD, the rs662 genetic variants having a crucial role. Although the promotion of oxidative stress by autoantibodies has been suggested in some conditions, as anti-phospholipid syndrome (APS) [39], this was not clear in RA, where APS-related autoantigens are not relevant immunodominant epitopes. Therefore, different autoimmune-mediated mechanisms may be responsible of oxidative status in different conditions, thus supporting the need for accurate patient stratification and tailored medicine in the clinical setting.

A key result of our report is the association between antiPON1 antibodies and sICAM levels. ICAM expression is known to be up-regulated by oxidative stress $[14,40]$ and similar results have been reported for sICAM levels [41]. Actually, oxidative stimuli promote ICAM shedding [42]. Interestingly, ICAM expression is also under the control of several pathways which have been reported to be triggered by certain autoantibodies [43].

Therefore, anti-PON1 antibodies could interfere with PON1 activity, thus impairing the HDL ability to scavenge reactive oxidative species and thus promoting an oxidant-prone milieu which may result in enhanced lipid peroxidation. This could in turn result in an up-regulation and shedding of ICAM, as a consequence of endothelial activation in response to oxidant stimuli. A progressive endothelial activation in a scenario of chronic inflammation and lipoprotein oxidation might result in an accelerated atherosclerosis development. This phenomenon is known to be especially relevant in low HDL scenarios [44], which is a common feature of RA. Moreover, a link between sICAM and biomarkers of oxidative stress depending on HDL levels has been reported [45]. Accordingly, smoking habit, a strong inducer of lipid peroxidation, has also been related to increased CVD rates in subjects with low PON1 activity [46]. These ideas are in line with the greater frequency of $\mathrm{CV}$ events in RA patients harbouring the QQ variant [20] reported by our group.

The fact that oxidative stress has an early role in CVD development may explain, at least in part, the lack of association between anti-PON1 antibodies and CVD in this work. Since the oxidative stress plays an early role in CVD pathogenesis [14], anti-PON1-mediated PON1 impairment may be related to other subclinical surrogate markers of CVD, such as endothelial dysfunction or cIMT. This idea is supported by the association between anti-PON1 levels and sICAM. It has been described that SICAM is a very early marker of future CV events [47], whereas other CAMs reflect the presence of already advanced atherosclerotic progression $[48,49]$. These lines of evidence are in line with the notion of the 'second hit' needed after PON1 
impairment for CVD promotion. In this sense, the negative association between anti-PON1 antibodies and $\mathrm{NO}_{x}$ serum levels reinforce this hypothesis. On the one hand, reduced NO synthesis is the main trigger of endothelial dysfunction, particularly in the early steps of atherosclerosis. Decreased NO production may be caused by a depletion of the bioavailability of tetrahydrobiopterin $\left(\mathrm{BH}_{4}\right)$ from endothelial nitric oxide synthase (eNOS) by oxidative stress [50,51]. This phenomenon leads to eNOS uncoupling, shifting this enzymatic activity from a protective NO-producing activity, towards a dysfunctional superoxide ion-producing activity, thereby perpetuating this loop [52]. Actually, decreased NO serum levels have been reported in other conditions hallmarked by oxidative stress and CV risk (reviewed in [52]). Accordingly, diminished NO production has been related to reduced HDL levels [53] and decreased paraoxonase activity [54]. Overall, our results are in line with these previous findings and support a mechanistic role for the anti-PON1 antibodies in the earliest steps of endothelial activation/dysfunction, oxidative status playing a key role. However, whether this negative association between antiPON1 antibodies and $\mathrm{NO}_{x}$ levels is related to a clinically relevant endothelial dysfunction cannot be concluded in the present study. Therefore, a study of subclinical CVD in association with antiPON1 antibodies warrants further insight into the connection between autoantibody-mediated PON1 impairment, endothelial dysfunction, eNOS uncoupling and CVD.

Finally, our results shed some light on the inflammationoxidative stress axis and its relevance as a therapeutic target. Although some authors have suggested a link between TNF $\alpha$ and oxidative stress [55], our results fail to show such an association. Interestingly since $\mathrm{TNF} \alpha$-blockade showed no effect on anti-PON1 levels and antioxidant capacity, other therapies may be advisable in patients with high anti-PON1 levels. Although a slight effect on anti-HDL has been reported by our group [21], anti-PON1 antibodies were not affected, thus reinforcing the idea that certain complexity within autoantibodies systems in terms of response upon TNF $\alpha$-blockade exists in RA [56]. Furthermore, low sample size of our prospective study and short-term follow up of the patients recruited may be important limitations of our study. On the other hand, some therapeutic drugs are known to counteract oxidative stress linked to inflammation or endothelial activation in other conditions [39]. Among them, statins, $N$-acetyl cysteine and coenzyme Q10 are promising compounds. Similarly, fenofibrates have been reported to abrogate the HDL-mediated increase of sICAM [44]. Therefore, anti-PON1 antibodies may provide a rationale for treatment decision-making in the clinical setting.

Overall, our approach allowed us to suggest the involvement of a novel potential player in CVD in RA by investigating new candidate epitopes in HDL. Interestingly, this approach shares some similarities with the research of the fine specificity of ACPA antibodies in RA [57], which has provided not only valuable insight on new relevant immunodominant peptides, but also new clues for the clinical management of this condition. Looking at these similarities, one can speculate that investigation on the 'fine specificity' of anti-HDL antibodies will bring us priceless information to delineate the links between CVD and HDL structure, whose complexity is merely started to be appreciated. Ac- tually, the lack of association between anti-PON1 and anti-HDL suggest the existence of multiple specificities. Since anti-PON1 antibodies were not associated with disease activity, clinical features or treatments in RA, it is tempting to speculate that some alterations within HDL structure are needed to make PON1 an accessible epitope for the generation of autoantibodies. In fact, changes in HDL structure have been reported in response to the inflammatory burden in RA [58]. Interestingly, when RA patients were stratified according to disease activity, those with moderate activity (DAS28 > 3.2) showed a positive correlation between both types of antibodies ( $r=0.228, P=0.013)$, being stronger in patients with established disease $(r=0.331, P=0.002)$. On the contrary, this correlation was absent from patients with milder disease activity (DAS28 $<3.2)(r=-0.079, P=0.523)$. Therefore, the findings herein presented point to a pivotal role for inflammatory-mediated changes within HDL in the origin of antiPON1 autoantibodies and warrants further studies to unravel the complex HDL 'fine specificity'.

In conclusion, we report for the first time the presence of anti-PON1 antibodies in RA in association with impaired PON1 activity, oxidative status and surrogate markers of endothelial activation and dysfunction. Collectively, our data point towards anti-PON1 antibodies as the missing link between autoimmunity and oxidative stress in RA, PON1 impairment and rs662 variants having a crucial role. These antibodies may be a promising tool for patient stratification and clinical management in RA and other conditions.

\section{CLINICAL PERSPECTIVES}

- In addition to serum levels, serum lipids seem to be functionally impaired in RA.

- The presence of high levels of IgG anti-PON1 antibodies in RA patients may explain not only the decreased PON1 activity, but also its connections with the antioxidant status and the endothelial activation. Moreover, a strong gene-environment interaction was observed.

- Anti-PON1 antibodies could have a pivotal role in the crosstalk between lipid abnormalities and inflammation in RA by being the missing link between autoimmunity and oxidative stress in RA. Therefore, anti-PON1 antibodies may be considered as promising early biomarkers of cardiovascular risk in RA patients, with potential use in the clinical setting for $\mathrm{CV}$ risk stratification and early treatment consideration.

\section{AUTHOR CONTRIBUTION}

Javier Rodríguez-Carrio performed most of the experimental procedures, carried out the statistical analyses and drafted the manuscript. Patricia López and Raquel López-Mejías performed some experimental procedures. Mercedes Alperi-López, Francisco BallinaGarcía and Francisco Abal were in charge of patients' recruitment and clinical data collection. Miguel González-Gay had an important role in the interpretation and discussion of the results. Ana Suárez conceived the study, designed the protocols and drafted and edited 
the manuscript. All authors read and approved the final version of the manuscript.

\section{FUNDING}

This work was supported by the European Union FEDER funds and 'Fondo de Investigación Sanitaria' (ISCIII, Health Ministry, Spain) [grant numbers PI12/00523, PI12/00060 and PI15/00525]; the RETICS Programs (ISCIII, Health Ministry, Spain) [grant number RD12/0009 (RIER)]; the Spanish Society for Rheumatology (SER) [grant number xxx]; the FICYT (Fundación para el fomento en Asturias de la Investigación Científica aplicada y la Tecnología) [grant number GRUPIN14-043 (to J.R.-C.)]; and the RETICS Program (RIER) [grant number RD12/0009/0013 (to R.L.M.)].

\section{REFERENCES}

1 del Rincón, I.D., Williams, K., Stern, M.P., Freeman, G.L. and Escalante, A. (2001) High incidence of cardiovascular events in a rheumatoid arthritis cohort not explained by traditional cardiac risk factors. Arthritis Rheum. 44, 2737-2745 CrossRef PubMed

2 Wållberg-Jonsson, S., Johansson, H., Öhman, M.L. and Rantapää-Dahlqvist, S. (1999) Extent of inflammation predicts cardiovascular disease and overall mortality in seropositive rheumatoid arthritis. A retrospective cohort study from disease onset. J. Rheumatol. 26, 2562-2571 PubMed

3 Gonzalez-Gay, M.A., Gonzalez-Juanatey, C., Lopez-Diaz, M.J., Piñeiro, A., Garcia-Porrua, C., Miranda-Filloy, J.A. et al. (2007) HLA-DRB1 and persistent chronic inflammation contribute to cardiovascular events and cardiovascular mortality in patients with rheumatoid arthritis. Arthritis Rheum. 57, 125-132 CrossRef PubMed

4 Dessein, PH., Joffe, B.I., Veller, M.G., Stevens, B.A., Tobias, M., Reddi, K. et al. (2005) Traditional and nontraditional cardiovascular risk factors are associated with atherosclerosis in rheumatoid arthritis. J. Rheumatol. 32, 435-442 PubMed

5 Robertson, J., Peters, M.J., McInnes, I.B. and Sattar, N. (2013) Changes in lipid levels with inflammation and therapy in RA: a maturing paradigm. Nat. Rev. Rheumatol. 9, 513-523 CrossRef PubMed

6 Choy, E. and Sattar, N. (2009) Interpreting lipid levels in the context of high-grade inflammatory states with a focus on rheumatoid arthritis: a challenge to conventional cardiovascular risk actions. Ann. Rheum. Dis. 68, 460-469 CrossRef PubMed

7 Myasoedova, E., Crowson, C.S., Kremers, H.M., Roger, V.L. Fitz-Gibbon, P.D., Therneau, T.M. et al. (2011) Lipid paradox in rheumatoid arthritis: the impact of serum lipid measures and systemic inflammation on the risk of cardiovascular disease. Ann. Rheum. Dis. 70, 482-487 CrossRef PubMed

8 van Vollenhoven, R.F., Fleischmann, R., Cohen, S., Lee, E.B., Garcia Meijide, J.A., Wagner, S. et al. (2012) Tofacitinib or adalimumab versus placebo in rheumatoid arthritis. N. Engl. J. Med. 367, 508-519 CrossRef PubMed

9 Charles-Schoeman, C., Watanabe, J., Lee, Y.Y., Furst, D.E., Amjadi, S., Elashoff, D. et al. (2009) Abnormal function of high-density lipoprotein is associated with poor disease control and an altered protein cargo in rheumatoid arthritis. Arthritis. Rheum. 60, 2870-2879 CrossRef PubMed

10 Charles-Schoeman, C., Lee, Y.Y., Grijalva, V., Amjadi, S., FitzGerald, J., Ranganath, V.K. et al. (2012) Cholesterol efflux by high density lipoproteins is impaired in patients with active rheumatoid arthritis. Ann. Rheum. Dis. 71, 1157-1162 CrossRef PubMed
11 Mackness, M.I., Arrol, S. and Durrington, P.N. (1991) Paraoxonase prevents accumulation of lipoperoxides in low-density lipoprotein. FEBS Lett. 286, 152-154 CrossRef PubMed

12 Costa, L.G., Cole, T.B., Jarvik, G.P. and Furlong, C.E. (2003) Functional genomic of the paraoxonase (PON1) polymorphisms: effects on pesticide sensitivity, cardiovascular disease, and drug metabolism. Annu. Rev. Med. 54, 371-392 CrossRef PubMed

13 Holvoet, P. and Collen, D. (1998) Oxidation of low density lipoproteins in the pathogenesis of atherosclerosis. Atherosclerosis 137 (Suppl), S33-S38 CrossRef PubMed

14 Nofer, J., Kehrel, B., Fobker, M., Levkau, B., Assmann, G. and von Eckardstein, A. (2002) Review article HDL and arteriosclerosis: beyond reverse cholesterol transport. Atherosclerosis 161, 1-16 CrossRef PubMed

15 Costa, L.G., Vitalone, A., Cole, T.B. and Furlong, C.E. (2005) Modulation of paraoxonase (PON1) activity. Biochem. Pharmacol. 69, 541-550 CrossRef PubMed

16 Ombres, D., Pannitteri, G., a, Montali, a, Candeloro, Seccareccia, F., Campagna, F. et al. (1998) The gln-Arg192 polymorphism of human paraoxonase gene is not associated with coronary artery disease in italian patients. Arterioscler. Thromb. Vasc. Biol. 18, 1611-1616 CrossRef PubMed

17 Ruiz, J., Blanche, H., James, R.W., Garin, M.C., Vaisse, C., Charpentier, G. et al. (1995) Gln-Arg192 polymorphism of paraoxonase and coronary heart disease in type 2 diabetes. Lancet 346, 869-872 CrossRef PubMed

18 Sentí, M., Tomás, M., Marrugat, J. and Elosua, R. (2001) Paraoxonase1-192 polymorphism modulates the nonfatal myocardial infarction risk associated with decreased HDLs. Arterioscler. Thromb. Vasc. Biol. 21, 415-420 CrossRef PubMed

19 Koch, M., Hering, S., Barth, C., Ehren, M., Enderle, M.D. and Pfohl, M. (2001) Paraoxonase 1192 Gln/Arg gene polymorphism and cerebrovascular disease: interaction with type 2 diabetes. Exp. Clin. Endocrinol. Diabetes 109, 141-145 CrossRef PubMed

20 Rodríguez-Carrio, J., López-Mejías, R., Alperi-López, M., López, P., Ballina-García, F.J., González-Gay, M.Á. et al. (2016) PON activity is modulated by rs662 polymorphism and IgG anti-HDL antibodies in rheumatoid arthritis patients: potential implications for CV disease. Arthritis Rheumatol. 68, 1367-1376 CrossRef PubMed

21 Rodríguez-Carrio, J., Alperi-López, M., López, P., Ballina-García, F.J., Abal, F. and Suárez, A. (2015) Antibodies to high-density lipoproteins are associated with inflammation and cardiovascular disease in rheumatoid arthritis patients. Transl. Res. 166, 529-539 $\underline{\text { CrossRef }}$ PubMed

22 Batuca, J.R., Ames, PRJ, Amaral, M., Favas, C., Isenberg, D.A. and Delgado Alves, J. (2009) Anti-atherogenic and anti-inflammatory properties of high-density lipoprotein are affected by specific antibodies in systemic lupus erythematosus. Rheumatology 48, 26-31 CrossRef PubMed

23 Romitelli, F., Santini, S.A., Chierici, E., Pitocco, D., Tavazzi, B., Amorini, A.M. et al. (2007) Comparison of nitrite/nitrate concentration in human plasma and serum samples measured by the enzymatic batch Griess assay, ion-pairing HPLC and ion-trap GC-MS: the importance of a correct removal of proteins in the Griess assay. J. Chromatogr. B Analyt. Technol. Biomed. Life Sci. 851, 257-267 CrossRef PubMed

24 Carbone, F., Nencioni, A., Mach, F., Vuilleumier, N. and Montecucco, F. (2013) Evidence on the pathogenic role of auto-antibodies in acute cardiovascular diseases. Thromb. Haemost. 109, 854-868 CrossRef PubMed

25 El-Banna, H. and Jiman-Fatani, A. (2014) Anti-cyclic citrullinated peptide antibodies and paraoxonase-1 polymorphism in rheumatoid arthritis. BMC Musculoskelet. Disord. 15, 379 CrossRef PubMed

26 Tanimoto, N., Kumon, Y., Suehiro, T., Ohkubo, S., Ikeda, Y., Nishiya, K. et al. (2003) Serum paraoxonase activity decreases in rheumatoid arthritis. Life Sci. 72, 2877-2885 CrossRef PubMed 
27 Delgado Alves, J., Ames, P.R.J., Donohue, S., Stanyer, L., Nourooz-Zadeh, J., Ravirajan, C. et al. (2002) Antibodies to high-density lipoprotein and beta2-glycoprotein I are inversely correlated with paraoxonase activity in systemic lupus erythematosus and primary antiphospholipid syndrome. Arthritis. Rheum. 46, 2686-2694 CrossRef PubMed

28 Charles-Schoeman, C., Lee, Y.Y., Shahbazian, A., Gorn, A.H., FitzGerald, J., Ranganath, V.K. et al. (2013) Association of paraoxonase 1 gene polymorphism and enzyme activity with carotid plaque in rheumatoid arthritis. Arthritis. Rheum. 65, 2765-2772 CrossRef PubMed

29 Bhattacharyya, T., Nicholls, S.J., Topol, E.J., Zhang, R., Yang, X., Schmitt, D. et al. (2008) Relationship of paraoxonase 1 (PON1) gene polymorphisms and functional activity with systemic oxidative stress and cardiovascular risk. JAMA 299, 1265-1276 CrossRef PubMed

30 Shih, D.M., Xia, Y.R., Wang, X.P., Miller, E., Castellani, L.W., Subbanagounder, G. et al. (2000) Combined serum paraoxonase knockout/apolipoprotein E knockout mice exhibit increased lipoprotein oxidation and atherosclerosis. J. Biol. Chem. 275, 17527-17535 CrossRef PubMed

31 Cabana, V.G. (2003) Serum paraoxonase: effect of the apolipoprotein composition of $\mathrm{HDL}$ and the acute phase response. J. Lipid Res. 44, 780-792 CrossRef PubMed

32 Sorenson, R.C., Bisgaier, C.L., Aviram, M., Hsu, C., Billecke, S. and La Du, B.N. (1999) Human serum paraoxonase/arylesterase's retained hydrophobic N-terminal leader sequence associates with HDLs by binding phospholipids: apolipoprotein A-I stabilizes activity. Arterioscler. Thromb. Vasc. Biol. 19, 2214-2225 CrossRef PubMed

33 Liu, C.K., Lyass, A., Larson, M.G., Massaro, J.M., Wang, N., D'Agostino, R.B. et al. (2016) Biomarkers of oxidative stress are associated with frailty: the Framingham Offspring Study. Age (Dordr) 38, 1 CrossRef PubMed

34 de Gonzalo-Calvo, D., de Luxán-Delgado, B., Rodríguez-González, S., García-Macia, M., Suárez, F.M., Solano, J.J. et al. (2012) Oxidative protein damage is associated with severe functional dependence among the elderly population: a principal component analysis approach. J. Gerontol. A Biol. Sci. Med. Sci. 67, 663-670 CrossRef PubMed

35 Rosenson, R.S., Brewer, H.B., Ansell, B.J., Barter, P., Chapman, M.J., Heinecke, J.W. et al. (2015) Dysfunctional HDL and atherosclerotic cardiovascular disease. Nat. Rev. Cardiol. 13, 48-60 CrossRef PubMed

36 Navab, M., Reddy, S.T., Van Lenten, B.J., Anantharamaiah, G.M. and Fogelman, A.M. (2009) The role of dysfunctional HDL in atherosclerosis. J. Lipid Res. 50 (Suppl), S145-S149 CrossRef PubMed

37 Fisher, E.A., Feig, J.E., Hewing, B., Hazen, S.L. and Smith, J.D. (2012) High-density lipoprotein function, dysfunction, and reverse cholesterol transport. Arterioscler. Thromb. Vasc. Biol. 32, 2813-2820 CrossRef PubMed

38 Shih, D.M., Gu, L., Hama, S., Xia, Y.R., Navab, M., Fogelman, A.M. et al. (1996) Genetic-dietary regulation of serum paraoxonase expression and its role in atherogenesis in a mouse model. J. Clin. Invest. 97, 1630-1639 CrossRef PubMed

39 López-Pedrera, C., Barbarroja, N., Jimenez-Gomez, Y., Collantes-Estevez, E., Aguirre, M.A. and Cuadrado, M.J. (2016) Oxidative stress in the pathogenesis of atherothrombosis associated with anti-phospholipid syndrome and systemic lupus erythematosus: new therapeutic approaches. Rheumatology (Oxford)

Q5

40 Tumur, Z., Shimizu, H., Enomoto, A., Miyazaki, H. and Niwa, T. (2010) Indoxyl sulfate upregulates expression of ICAM-1 and MCP-1 by oxidative stress-induced NF-kappaB activation. Am. J. Nephrol. 31, 435-441 CrossRef PubMed

41 Sadowska, A.M., van Overveld, F.J., Górecka, D., Zdral, A., Filewska, M., Demkow, U.A. et al. (2005) The interrelationship between markers of inflammation and oxidative stress in chronic obstructive pulmonary disease: modulation by inhaled steroids and antioxidant. Respir. Med. 99, 241-249 CrossRef PubMed
42 Essick, E., Sithu, S., Dean, W. and D'Souza, S. (2008) Pervanadate-induced shedding of the intercellular adhesion molecule (ICAM)-1 ectodomain is mediated by membrane type-1 matrix metalloproteinase (MT1-MMP). Mol. Cell Biochem. 314, 151-159 CrossRef PubMed

43 Ksiazek, K., Mikuła-Pietrasik, J., Catar, R., Dworacki, G., Winckiewicz, M., Frydrychowicz, M. et al. (2010) Oxidative stress-dependent increase in ICAM-1 expression promotes adhesion of colorectal and pancreatic cancers to the senescent peritoneal mesothelium. Int. J. cancer 127, 293-303 PubMed

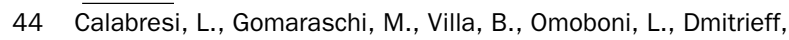
C. and Franceschini, G. (2002) Elevated soluble cellular adhesion molecules in subjects with low HDL-cholesterol. Arterioscler. Thromb. Vasc. Biol. 22, 656-661 CrossRef PubMed

45 Wan Ahmad,, W.N.H., Sakri, F, Mokhsin, A., Rahman, T., Mohd Nasir, N., Abdul-Razak, S. et al. (2015) Low serum high density lipoprotein cholesterol concentration is an independent predictor for enhanced inflammation and endothelial activation. PLoS One 10, e0116867 CrossRef PubMed

46 Senti, M., Aubo, C., Tomas, M., Sentí, M., Aubó, C. and Tomás, M. (2000) Differential effects of smoking on myocardial infarction risk according to the Gln/Arg 192 variants of the human paraoxonase gene. Metabolism 49, 557-559 CrossRef PubMed

47 Ridker, P.M., Hennekens, C.H., Roitman-Johnson, B., Stampfer, M.J. and Allen, J. (1998) Plasma concentration of soluble intercellular adhesion molecule 1 and risks of future myocardial infarction in apparently healthy men. Lancet 351, 88-92 CrossRef PubMed

48 Wallén, N.H., Held, C., Rehnqvist, N. and Hjemdahl, P. (1999) Elevated serum intercellular adhesion molecule-1 and vascular adhesion molecule-1 among patients with stable angina pectoris who suffer cardiovascular death or non-fatal myocardial infarction. Eur. Heart J. 20, 1039-1043 CrossRef PubMed

49 Mulvihill, N.T., Foley, J.B., Murphy, R.T., Curtin, R., Crean, P.A. and Walsh, M. (2001) Risk stratification in unstable angina and non-Q wave myocardial infarction using soluble cell adhesion molecules. Heart 85, 623-627 CrossRef PubMed

50 Gunnett, C.A., Lund, D.D., McDowell, A.K., Faraci, F.M. and Heistad, D.D. (2005) Mechanisms of inducible nitric oxide synthase-mediated vascular dysfunction. Arterioscler. Thromb. Vasc. Biol. 25, 1617-1622 CrossRef PubMed

51 Vásquez-Vivar, J., Kalyanaraman, B., Martásek, P., Hogg, N., Masters, B.S., Karoui, H. et al. (1998) Superoxide generation by endothelial nitric oxide synthase: the influence of cofactors. Proc. Natl. Acad. Sci. U.S.A. 95, 9220-9225 CrossRef PubMed

52 Förstermann, U. (2010) Nitric oxide and oxidative stress in vascular disease. Pflügers Arch. Eur. J. Physiol. 459, 923-939 CrossRef

53 Vanizor, B., Orem, A., Karahan, S.C., Kiran, E., Erem, C., Aliyazicioğlu, R. et al. (2001) Decreased nitric oxide end-products and its relationship with high density lipoprotein and oxidative stress in people with type 2 diabetes without complications. Diabetes Res. Clin. Pract. 54, 33-39 CrossRef PubMed

54 Delgado Alves, J., Mason, L.J., Ames, PR.J., Chen, P.P, Rauch, J., Levine, J.S. et al. (2005) Antiphospholipid antibodies are associated with enhanced oxidative stress, decreased plasma nitric oxide and paraoxonase activity in an experimental mouse model. Rheumatology (Oxford) 44, 1238-1244

CrossRef PubMed

55 Victor, V.M., Rovira-Llopis, S., Bañuls, C., Diaz-Morales, N., Martinez de Marañon, A., Rios-Navarro, C. et al. (2016) Insulin resistance in PCOS patients enhances oxidative stress and leukocyte adhesion: role of myeloperoxidase. PLoS One 11, e0151960 CrossRef PubMed

56 De Rycke, L., Verhelst, X., Kruithof, E., Van den Bosch, F., Hoffman, IEA, Veys, E.M. et al. (2005) Rheumatoid factor, but not anti-cyclic citrullinated peptide antibodies, is modulated by infliximab treatment in rheumatoid arthritis. Ann. Rheum. Dis. 64, 299-302 CrossRef PubMed 
57 Lundberg, K., Bengtsson, C., Kharlamova, N., Reed, E., Jiang, X., Kallberg, H. et al. (2013) Genetic and environmental determinants for disease risk in subsets of rheumatoid arthritis defined by the anticitrullinated protein/peptide antibody fine specificity profile. Ann. Rheum. Dis. 72, 652-658 $\underline{\text { CrossRef PubMed }}$
58 Watanabe, J., Charles-Schoeman, C., Miao, Y., Elashoff, D., Lee, Y.Y., Katselis, G. et al. (2012) Proteomic profiling following immunoaffinity capture of high-density lipoprotein: association of acute-phase proteins and complement factors with proinflammatory high-density lipoprotein in rheumatoid arthritis. Arthritis Rheum. 64, 1828-1837 CrossRef PubMed

Received 27 May 2016/28 June 2016; accepted 12 August 2016

Accepted Manuscript online 12 August 2016, doi: 10.1042/CS20160374 